\title{
Metáforas en Lengua de Señas Chilena
}

\section{Metaphors in Chilean Sign Language}

\author{
Carolina Becerra \\ Universidad Católica de la Santísima Concepción
}

\begin{abstract}
Este estudio describe las características del lenguaje metafórico de personas sordas chilenas y su impacto en la comprensión lingüística. La relevancia de esta pregunta radica en la escasez de investigaciones realizadas, particularmente a nivel nacional. Se desarrolló un estudio cualitativo en base a análisis de videos de sujetos sordos en habla espontánea. Se confeccionó una lista de metáforas conceptuales y no conceptuales en Lengua de Señas Chilena. Posteriormente se evaluó su comprensión en un grupo de sujetos sordos, educados con modalidad comunicativa de lengua de señas. Los resultados obtenidos permiten observar la existencia de metáforas propias de la cultura sorda. Ellas serían coherentes con las particulares experiencias de los sujetos sordos y no necesariamente concuerdan con el lenguaje oral.
\end{abstract}

Palabras Clave: lengua de señas, metáforas, sordos.

\begin{abstract}
The present study examined the characteristics of Chilean deaf people's metaphoric language and its relevance in linguistic comprehension. This key question is based in the scarcity of studies conducted in Chile. A qualitative study was developed, on the basis of analysis of videos of Chilean deaf people spontaneous sign language. A list of conceptual and no conceptual metaphors in Chilean sign language was developed. The comprehension of these metaphors was evaluated in a group of deaf subjets, educated using sign language communication. The results identify the existence of metaphors of the deaf culture. These methaphors would be coherent with the particular experiences of deaf subjets and do not necessarily agree with spoken language.
\end{abstract}

Keywords: sign language, metaphors, deaf.

A pesar que el tema de las metáforas ha despertado un creciente interés de investigación en Psicología, en relación a las personas sordas, este campo aún está en desarrollo. Las investigaciones no son abundantes y se orientan principalmente a la evaluación de la capacidad comprensiva de estas personas frente a metáforas propias del lenguaje oral (Gilbertson \& Kahmi, 1995; Iran-Nejad, Rittenhouse \& Morreau, 1981; Rittenhouse \& Kenyon, 1991; Wolgelmuth, Kahmi \& Lee, 1998). Algunos estudios en American Sign Language ${ }^{1}$ (en adelante ASL) han descrito una pobreza literal en la comprensión de metáforas en sujetos sordos (Boatner \& Gates, 1975; Conrad, 1979; Furth, 1973; Iran-Nejad, Rittenhouse \& Morreau, 1981; Johnson \& Myklebust, 1967). En ellos se reporta un considerable número de fallas para la comprensión de conceptos metafóricos si se les compara con sus pares oyentes (Takashi, 1999).

Carolina Becerra Sepúlveda, Facultad de Educación, Universidad Católica de la Santísima Concepción, Chile.

La correspondencia relativa a este artículo debe ser dirigida a la autora, Facultad de Educación, Universidad Católica de la Santísima Concepción, Alonso de Ribera 2850, Concepción, Chile. E-mail: carolinabecerra@ucsc.cl

1 Sigla correspondiente a la Lengua de Señas Americana.
A partir del análisis de la configuración de la lengua de señas, nuevas investigaciones (Brennan, 1994; Giuranna \& Giuranna, 2000; Jarque, 2005; Pizzuto, Russo \& Giuranna, 2001; Russo, 2005; Taub, 2001; Wilcox, 1993, 2000) muestran la presencia de metáforas propias en ASL, BSL ${ }^{1}, \mathrm{LSC}^{2}$ y LIS 3 . Ellas no necesariamente coinciden con el lenguaje oral. Esto ha derivado en controversias respecto de las capacidades expresivas de esta lengua.

Lo anterior conlleva un debate de dos posturas teóricas que invitan además a un análisis riguroso de la expresión metafórica de la lengua de señas. El presente estudio pretende argumentar empíricamente que las conclusiones respecto de las capacidades cognitivas y lingüísticas de las personas sordas debieran desprenderse del análisis de la estructura de su propia lengua y no basarse en su manejo de la lengua oral.

Se propone un estudio que mantenga a la base la configuración de la lengua de señas. Se pretende indagar acerca de la existencia de metáforas en Lengua de Señas Chilena, estudiando sus características distintivas y su rol en la comprensión lingüística.

\footnotetext{
Sigla correspondiente a la Lengua de Señas Británica.

Sigla correspondiente a la Lengua de Señas Catalana.

Sigla correspondiente a la Lengua de Señas Italiana.
} 


\section{Antecedentes Teóricos y Empíricos}

\section{Doble Mapeo y Metáforas en Lengua de Señas}

Durante largo tiempo, se argumentó que las lenguas de señas eran incapaces de expresar conceptos abstractos (Boatner \& Gates, 1975; Conrad, 1979; Furth, 1973; Johnson \& Myklebust, 1967). Estas posturas han sido centro de actuales debates, donde nuevos argumentos teóricos y empíricos (Brennan, 2005; Taub, 2001; Wilcox, 2000) pretenden reconocer y destacar el valor de la iconicidad en las lenguas de señas. Además, estas ideas han tomado mayor fuerza en el contexto de las metáforas, donde se plantea que "las metáforas permiten a las señas icónicas tener significados abstractos" (Taub, 2001, p. 3).

Como se puede ver la metáfora se relaciona con la iconicidad de esta lengua. Para Fauconnier (1994) las características icónicas de las señas son activadas durante los procesos cognitivos en línea y están destinadas a maximizar la semejanza entre dos dominios generalmente inconexos. Brennan (2005) agrega que en metáforas, las características icónicas de las señas tienen un papel en el proceso creativo de determinar una compatibilidad mental entre dos dominios diferentes.

Hasta acá es importante destacar que un ítem lingüístico que involucra iconicidad representa sólo un referente físico concreto. Así, el caso de la seña árbol, es puramente icónica: su forma se parece directamente a su significado y no constituye por tanto una metáfora. Pero Taub (2001) agrega que hay más que iconicidad en señas como pensar/penetrar, cuya forma se parece a un objeto emergiendo de la cabeza y atravesando una barrera. Esta forma puede ser traducida como: ella finalmente llegó al punto, y no tiene significado concreto. Para Taub (2001), este uso de una imagen concreta para describir un concepto abstracto es una instancia de metáfora, y pensar/penetrar es al mismo tiempo icónico y metafórico.

El mapeo representa uno de los avances de la teoría de la metáfora conceptual por sobre otras formas de analizar las metáforas. Para Taub (2001), los elementos esenciales de un mapeo incluyen: entidades; relaciones y acciones desde un dominio origen a un dominio meta; un establecimiento de cómo estos elementos se corresponden entre sí, y expresiones metafóricas que ejemplifican cada correspondencia. Para un ejemplo en ASL, Taub (2001) considera la analogía tirar objetos como comunicar ideas. Acá se muestra cómo los dominios de comunicar ideas y tirar objetos están vinculados para los hablantes: la idea corresponde al objeto; decir o explicar la idea corresponde a tirar el objeto a alguien; y comprender la idea corresponde a agarrar el objeto. Así, las piezas relevantes de un dominio están mapeadas en piezas relevantes de otro.

Taub (2001) indica que en esencia, las señas metafóricas en ASL son formadas por un doble mapeo: un mapeo metafórico desde el dominio conceptual concreto a uno abstracto y un mapeo icónico entre el dominio de origen concreto y las formas lingüísticas que lo representan. El resultado es que el dominio meta es presentado usando un dibujo icónico del dominio de origen. Por ejemplo, en inglés la seña metafórica pensar-chocar consiste de un dibujo icónico de un proyectil que choca con un muro. Denota un fracaso en la comunicación y es equivalente a la oración no puedo llegar a él.

La forma de funcionamiento del doble mapeo propuesto por Taub (2001) manifiesta la complejidad de la metáfora en lengua de señas. Además demuestra el proceso que realiza el señante para alcanzar su expresión metafórica. Taub (2001) indica que esta acción comienza con un concepto abstracto específico para ser expresado: por ejemplo el concepto de comunicar exitosamente una idea a pesar de la dificultad. El usuario del ASL sabrá qué parte del dominio de origen concreto corresponde a este dominio meta. En el mapeo de comunicar es enviar, la comunicación exitosa de una idea corresponde a enviar exitosamente un objeto de la cabeza a otra persona. Por otra parte, las dificultades en la comunicación corresponden a las dificultades de enviar. Así, el usuario de ASL va a crear una representación icónica de enviar exitosamente un objeto desde la cabeza de uno a pesar de una dificultad.

En este punto, el usuario de ASL tiene que hacer una elección: el concepto de dominio de origen concreto es muy general, y el proceso de construcción análoga requiere una imagen sensorial específica. Hay muchas formas posibles para enviar un objeto a otra persona: por correo, por mano, a través del aire, etc. Sin embargo en este caso la imagen se enfoca en particular en el movimiento de un proyectil como objeto. Luego, hay muchas formas posibles de dificultades al enviar objetos por el aire: el objeto puede llegar muy alto, puede irse en una dirección equivocada, o puede golpear una barrera. Cada dificultad se puede sobrellevar de diferentes maneras: el receptor puede saltar para alcanzarlo, o el objeto puede ser tirado con mayor fuerza para traspasar la barrera. En el caso 
de pensar-penetrar, la dificultad específica elegida es la barrera, y la manera específica de sobrellevarla es enviar el objeto con suficiente fuerza.

Así, la imagen completa seleccionada corresponde a "movimiento como proyectil de un objeto desde la cabeza de uno a través del aire hacia otra persona; el objeto golpea una barrera con suficiente fuerza para penetrarla" (Taub, 2001, p. 111). Esta imagen sería un equivalente a la idea: logré comunicar adecuadamente mi punto de vista. Es por tanto una expresión icónica y metafórica al mismo tiempo.

\section{Estudios Empiricos en ASL y Lengua de Señas Chilena}

A partir de su propuesta de doble mapeo, Taub (2001) desarrolla algunos estudios empíricos que le permiten proponer una clasificación detallada de ciertas metáforas. Para ello utilizó el siguiente registro:

1. El futuro está delante: En este mapeo, el futuro está conceptualizado delante de la persona de referencia, el pasado está detrás de la persona de referencia y el presente está co-ubicado con la persona. La distancia relativa en el espacio se corresponde a un tiempo relativo remoto. Por ejemplo, una vez a la semana en el futuro es visto como más cercano a la persona de referencia que diez años en el futuro (Taub, 2001).

2. Intimidad y proximidad: En este parámetro la metáfora da significancia a las locaciones relativas de los articuladores en el espacio de señalización. Parcialmente motiva las formas físicas de señas como: amar, resistir, amigo, amigo-cercano, casado y divorciado. En este mapeo, a mayor cercanía de los articuladores, mayor intimidad y el afecto mutuo entre las entidades.

3. Iconicidad metafórica e iconicidad pura en una seña metafórica: Para Taub (2001), este tipo de metáforas corresponde a un caso en el cual dos tipos diferentes de iconicidad se combinan con la iconicidad metafórica en la estructura de una sola seña.

4. Fusiones de señas: Esta forma de clasificación proviene de la propuesta de Wilcox (2005). La autora sugiere observar el fenómeno de fusiones de señas, las cuales son producidas en línea y sin esfuerzo por el signante. Adicionalmente Fauconnier (1994) indica que una mezcla de señas es un espacio mental en el cual una seña transmite una estructura de dos espacios. Para Wilcox (2005) el cruce de planos imaginativos generado por la esquematicidad de la seña, conllevaría finalmente a la metáfora.

En Chile, el tema de las metáforas en lengua de señas comienza progresivamente a recibir atención. En su primer estudio, Ibáñez, Becerra, López, Sirlopú y Cornejo (2005) observaron que el componente metafórico se encuentra íntimamente ligado al carácter icónico de cada seña. Además distinguieron metáforas de carácter lingüístico-cultural y corporales-experienciales, donde se evidencia un predominio de estas últimas. Concluyen que gran parte de las metáforas en Lengua de Señas Chilena difieren en relación a las del lenguaje oral o español hablado, especialmente aquellas de carácter lingüístico-cultural. Adicionalmente, observaron elementos comunes en ambas lenguas (español hablado y de señas), particularmente en las expresiones metafóricas de carácter corporal-experiencial (Ibáñez et al., 2005). Ellas se corresponderían con el funcionamiento corporal diario tanto en sordos como oyentes.

A pesar de los hallazgos y argumentos presentados en sus conclusiones, Ibáñez et al. (2005) plantean la necesidad de identificar metáforas específicas de la cultura sorda. Ello podría dar luces acerca de la influencia de la cultura en la estructuración del lenguaje metafórico. Lo interesante de asumir el desafío propuesto por Ibáñez et al. (2005), radica en la búsqueda de expresiones metafóricas propias en lengua de señas, basándose en un análisis que utilice doble mapeo. Ello permitiría su estudio desde una perspectiva diferente, que implica observar la especial configuración de la lengua de señas.

\section{Método}

La investigación se realizó mediante dos estudios. El primero de ellos recopiló información relativa a metáforas utilizadas por sujetos sordos. El segundo estudio evaluó la comprensión de estas metáforas en la comunidad sorda en general.

\section{Estudio 1}

\section{Participantes}

La muestra estuvo compuesta por un total de 28 participantes cuyas edades fluctuaron entre los 15 y 45 años. Estas personas presentaban una sordera profunda bilateral (según análisis de audiometría e informes médicos) y fueron educados con modalidad comunicativa de lengua de señas (particularmente Comunicación Total) desde temprana edad.

\section{Procedimiento}

En una primera aproximación se realizó una filmación a 28 sujetos en habla espontánea, que accedieron voluntariamente a 
participar y se encontraban en las dependencias de la Asociación de Sordos de Chile. Esta filmación registró las actividades e interacciones de los sujetos sordos en las dependencias de su Asociación, sin intervención de la investigadora. Posteriormente 15 de estas personas participaron voluntariamente en un focus group, donde se tocaron temáticas relativas al futuro y sus expectativas.

Luego de este focus group se invitó a tres personas (dos mujeres y un hombre) con edades entre 18 y 23 años a continuar participando del estudio. Las tres personas invitadas participaron de una entrevista semi-estructurada. Se abordaron temáticas relativas a la vida familiar y profesional, expectativas futuras y visión personal acerca de cómo la discapacidad puede afectar su integración a la sociedad.

\section{Instrumento}

Cada una de las entrevistas fue grabada con una cámara de video tradicional en cinta de $5 \mathrm{~mm}$.

La video-grabación de los 28 voluntarios en habla espontánea tuvo una duración total de 1 hora. La video-grabación correspondiente al focus group tuvo una duración de 45 minutos. La video-grabación de entrevista semi-estructurada a los tres sujetos que accedieron a participar voluntariamente tuvo una duración de 45 minutos por persona.

\section{Análisis de Datos}

Se realizó un análisis del material audiovisual, con apoyo de dos intérpretes bilingües de la Asociación de Sordos de Chile (ASOCH).

A partir del material recopilado y en base a las traducciones realizadas por los intérpretes, se elaboró una lista preliminar compuesta por 30 expresiones figuradas que incluían metonimias, ironía y humor. Es importante destacar que el objetivo de este estudio no consiste en realizar un registro exhaustivo de todos los diálogos, sino señalar los fenómenos metafóricos más importantes para proseguir con el Estudio 2.

\section{Estudio 2}

Esta fase evaluó el grado de comprensión, por parte de usuarios sordos señantes, de las metáforas en lengua de señas.

\section{Participantes}

La muestra estuvo compuesta por seis mujeres y seis hombres sordos profundos, de edades entre 18 y 35 años. Los participantes debían presentar una sordera profunda bilateral y un manejo fluido de la lengua de señas, como requisito para su inclusión en el estudio. La información respecto a la pérdida auditiva fue corroborada mediante informes médicos y audiometrías entregados por los voluntarios. Adicionalmente se indagó acerca de la modalidad de educación recibida (Comunicación Total).

Procedimiento

Se invitó a los 12 participantes a presentarse en las dependencias de la Pontificia Universidad Católica de Chile, en horario acordado con la investigadora. Las instrucciones entregadas consistieron en observar un video con expresiones metafóricas formuladas por otras personas e informar a la examinadora lo que comprendían en cada una de ellas. El énfasis estuvo puesto en que los voluntarios explicaran con sus propias palabras lo que comprendían a partir de la video-grabación.
Los datos fueron grabados y consignados en una lista de cotejo, donde se registró la correspondencia o no entre las respuestas de los participantes y el sentido de la metáfora.

Cada evaluación tuvo una duración aproximada de 45 minutos. En ocasiones este tiempo se extendió debido a información adicional entregada por participantes interesados en destacar las particularidades de su lengua.

\section{Instrumento}

La evaluación del material audiovisual de 19 metáforas en lengua de señas se llevó a cabo en una oficina de la Pontificia Universidad Católica de Chile, previa autorización del profesor correspondiente. En ella se utilizaron como recursos un computador y una cámara video grabadora digital montada sobre trípode, la cual registró el proceso. Se aplicó la lista de metáforas compuesta por un video digitalizado, que fue proyectado en programa Windows Movie Maker a sujetos sordos de manera individual.

\section{Análisis de Datos}

El abordaje de las expresiones metafóricas obtenidas en el Estudio 1 y la confección de la lista de 19 metáforas parte de la propuesta de doble mapeo (Taub, 2001). Las expresiones metafóricas seleccionadas necesariamente debían cumplir este requisito para su inclusión en el estudio.

A partir de los análisis de video se desprendieron 19 expresiones que fueron consignados en dos tablas diferentes: una para las metáforas conceptuales y otra para las metáforas no conceptuales. El material definitivo consistió en una lista de 19 metáforas traducidas al lenguaje español hablado. Posteriormente se confeccionó el material audiovisual para los 12 participantes del Estudio 2.

Las respuestas (concordantes o discordantes con el sentido otorgado) fueron consignadas en una lista de cotejo, para la posterior elaboración de estadísticos descriptivos. Además, la información correspondiente a las respuestas de cada una de las evaluaciones fue consignada en video y digitalizada. Posteriormente se tradujo al español escrito cada entrevista, generando un corpus para su análisis.

\section{Resultados}

\section{Resultados Estudio 1}

Esta etapa consistió en confeccionar una lista de metáforas conceptuales y no conceptuales en Lengua de Señas Chilena. Ella finaliza con la confección de dicha lista en material audiovisual.

\section{Confección de Lista de Metáforas}

Las grabaciones en habla espontánea obtenidas en esta primera etapa del estudio arrojaron un cuerpo de 30 expresiones figuradas en Lengua de Señas Chilena. De ellas se seleccionó un corpus de 19 metáforas. Para efectos de selección no se consideraron expresiones lingüísticas compuestas por metonimia, humor e ironía. La elección de cada 
Tabla 1

Metáforas no conceptuales

\begin{tabular}{lll}
\hline Traducción en lenguaje español & Tópico & Vehículo \\
\hline La política es charlatanería & Política & Charlatán + política \\
Las asignaturas se resignan/consienten & Asignatura & Resignarse, consentir \\
El fracaso es libertad & Fracasar & Liberarse \\
Los aprendizajes vienen y se guardan en la cabeza & Aprendizaje & Aprender + venir + cabeza \\
La persona es un caballo & Persona & Caballo + anteojeras \\
La oportunidad se toma y se cambia & Oportunidad & Tomar y mover \\
El progreso se desenrolla & Progreso & Desenrollar \\
El lenguaje se derrama & Lenguaje & Derramar \\
No tener tiempo es dar la hora & Tiempo & Reloj \\
Una profesión es un amor & Profesión (Ed. Física) & Estar enamorado \\
\hline
\end{tabular}

Tabla 2

Metáforas conceptuales

\begin{tabular}{|c|c|c|c|}
\hline Metáfora en lenguaje español & Contenido Meta & Origen & Categorización \\
\hline El cerebro explota & Estudiar & Explotar cerebro & La mente es un recipiente \\
\hline El pene se cae & Actividad Sexual & Caída del pene & Fuerza es arriba \\
\hline Las ilusiones se apartan & Decepción & Apartar, limpiar & Negativo es abajo \\
\hline Un problema se encamina & Problemas, amonestación & Camino & Los problemas son objetos \\
\hline El reto es una guerra & Reto & Guerra & Un reto es una guerra \\
\hline $\begin{array}{l}\text { Los problemas se lavan } \\
* \text { Los problemas son sucios }\end{array}$ & Problema & Lavarse las manos & Los problemas son objetos \\
\hline El cansancio está en la frente & Cansancio & Frente & La mente es un recipiente \\
\hline Las ideas son objetos separables & Ideas & Objeto & Ideas son objetos \\
\hline Los obstáculos se dejan en el camino & Obstáculo & Camino + lejos & La vida es un camino \\
\hline
\end{tabular}

metáfora se basó en la propuesta de doble mapeo sugerida por Taub (2001).

Posteriormente, y a partir de esta selección, se clasificaron las metáforas halladas en conceptuales y no conceptuales. La metáfora conceptual se analizó considerando un concepto concreto o físico que actúa como fuente o dominio origen, y que sirve para la comprensión de un concepto más abstracto o dominio meta. La metáfora no conceptual se analizó considerando conceptos de tópico y vehículo. A partir de este análisis se obtuvieron dos listas, tal como se muestra en las Tablas 1 y 2. Estas listas configuraron el punto de partida para la preparación del material audiovisual.

Una vez seleccionadas las metáforas más apropiadas para el estudio se editaron las imágenes correspondientes, lo que generó un material audio- visual digitalizado, compuesto por un cuerpo de 19 metáforas en Lengua de Señas Chilena.

\section{Categorización Metafórica, Mapeo Icónico y Mapeo Metafórico}

Para el análisis de las 19 expresiones halladas se consideraron conceptos de: categorización metafórica, mapeo icónico y doble mapeo (icónico y metafórico). En función de estos tópicos se describen algunos de los resultados obtenidos:

\section{Categorización metafórica}

\subsection{La mente es un contenedor: En los ejemplos que} siguen, los sujetos sordos utilizaron el concepto de la mente como un recipiente. Este contenedor está situado fundamentalmente en la cabeza, la 


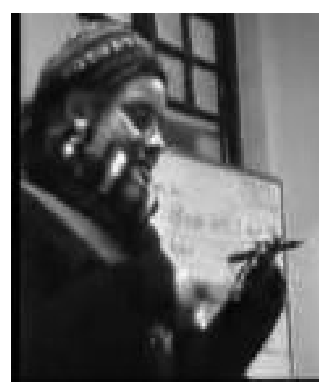

(a) Leer, leer

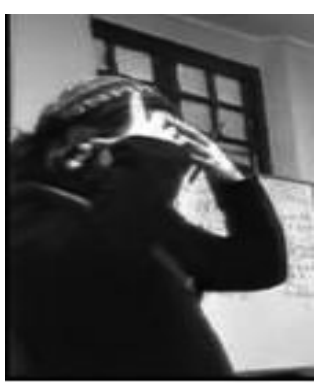

(b) Hinchar cabeza

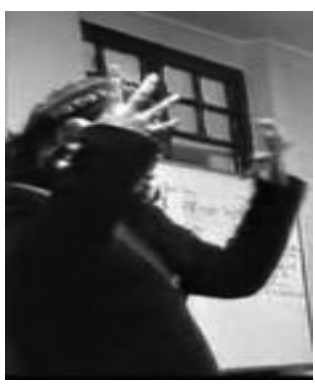

(c) Explotar

Figura 1. Traducción en lenguaje español: El cerebro explota.
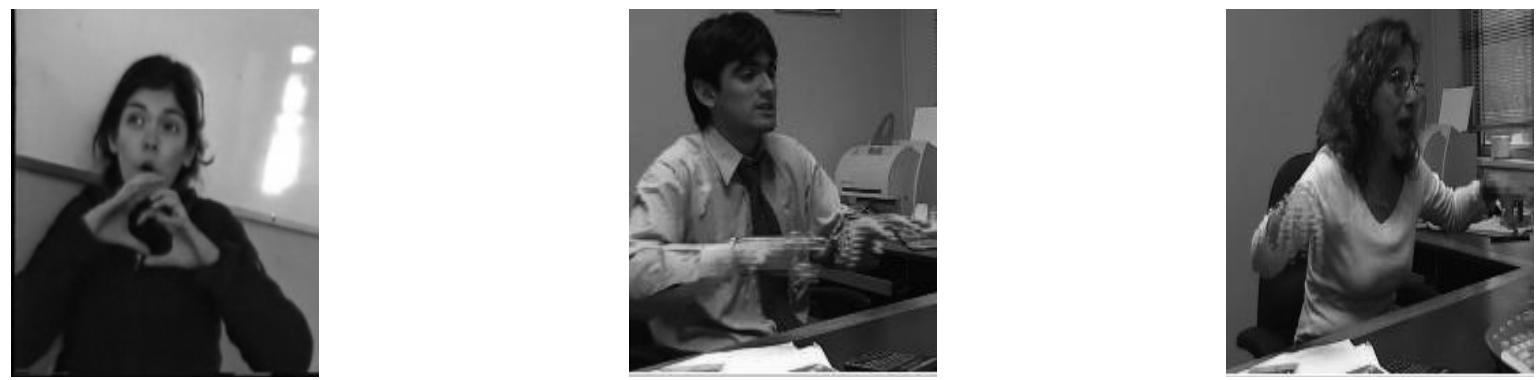

Figura 2. "Cosas". Traducción en lenguaje español: Las ideas son objetos.

cual almacena en sus "compartimientos", diversas experiencias de la vida cotidiana, tal como se muestra en la Figura 1.

1.2. Las ideas son objetos: $\mathrm{Al}$ igual que en $\mathrm{ASL}$, la Lengua de Señas Chilena también presenta elementos de materialización de ideas abstractas en objetos que pueden ser ordenados y reubicados en el espacio de acuerdo a las necesidades del emisor, tal como se presenta en la Figura 2.

En las tres imágenes de la Figura 2, los signantes toman dos ideas presentes en su mente y las materializan en "cosas". Pero se requiere su separación en dos espacios mentales diferentes (tal como se observa en la configuración de las manos), para poder explicar adecuadamente que se referirá a dos tipos de situaciones distintas que en algún momento de la conversación estarán de algún modo relacionadas.

Dentro de esta categorización, se ha podido observar también una nueva clasificación que guarda relación con el concepto visto de las ideas como objetos, pero que además pueden ser sometidos a fuerza física. De esta manera una idea o situación poco agradable, genera un problema, que también se concibe como un objeto.

Los problemas son objetos. Los sujetos entrevistados se referían a los problemas como objetos mani- pulables que además podían ser ubicados dentro de su propio mapa espacial. En este sentido, cualquier tipo de problemática podía ser encaminada (los obstáculos se dejan en el camino), lavada (me lavo las manos-frente a un problema-), o apartada (los problemas se apartan), tal como se muestra en el ejemplo de la Figura 3.

\section{Mapeo icónico}

\subsection{Metáforas espaciales sobre el futuro y lo desea-} do: Así como los gestos metafóricos espontáneos en sujetos oyentes presentan un mapeo corporal (Lakoff \& Johnson, 1999; McNeill, 1992), en sujetos sordos se produce un fenómeno similar, que les permite orientar situaciones positivas hacia arriba y negativas hacia abajo. El progreso y el futuro, se ubican hacia arriba y delante, mientras que el retraso y el fracaso se ubican hacia atrás y hacia abajo respectivamente, tal como se observa en la Figura 4.

En el ejemplo, la persona utiliza el mapeo espacial hacia delante (Figura 4b), para indicar que el progreso se produce paulatinamente en relación al futuro, y que el futuro se ubica delante de él. Además, el gesto de desenrollar se ubica levemente orientado hacia la zona superior, lo cual sumado a 


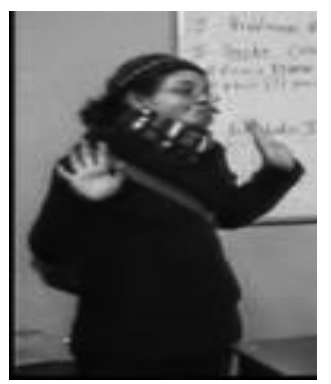

(a) No me importa

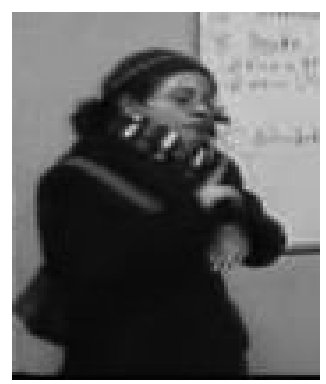

(b) $\mathrm{No}$

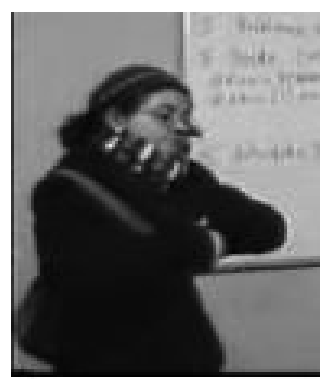

(c) Lavar manos

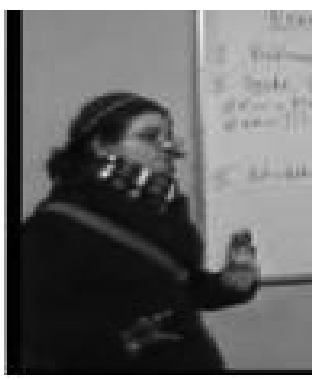

(d) Apartarse

Figura 3. Los problemas se lavan. Traducción en lenguaje español: Me lavo las manos.

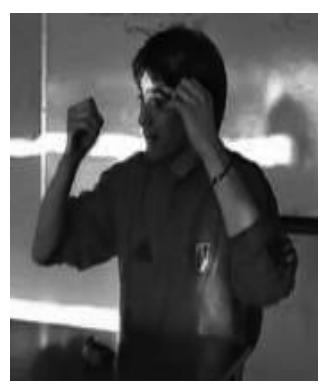

(a) Crecer, avanzar, progresar

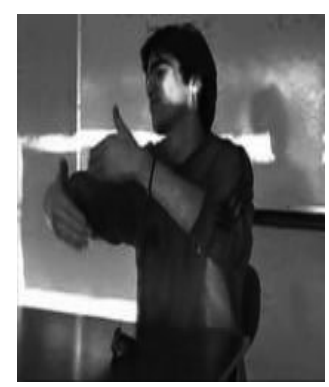

(b) Desenrollar (entendido como "desarrollar")

Figura 4. Desarrollo. Traducción en lenguaje español: El progreso se desenrolla.

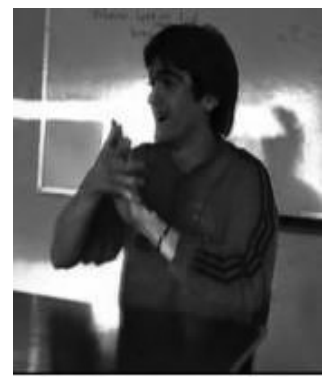

(a) Lengua de señas

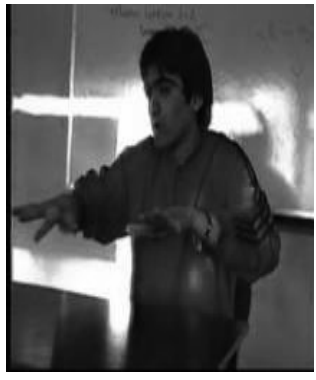

(b) Derramar

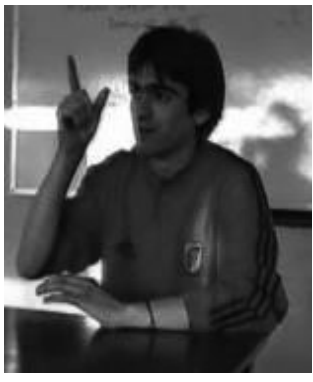

(c) Ideas, informaciones

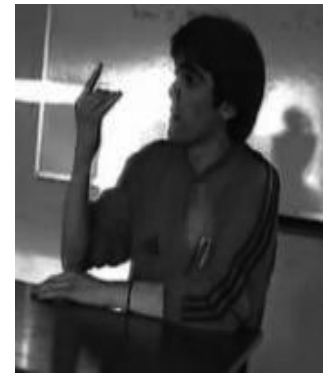

(d) Universidad

Figura 5. Traducción en lenguaje español: El lenguaje se derrama.

la idea de crecer, avanzar, progresar (ver Figura 4a), le entrega un carácter de futuro positivo. Por ende, desenrollar, aún cuando no refiera específicamente la seña desarrollo, está indicando el sentido de desarrollar. De esta manera se entiende el tema del progreso como un desarrollo positivo y no como el acto de desenrollar algún objeto.

2.2. Metáforas espaciales sobre el transporte de información: Se le entrega al lenguaje (y a la lengua de señas en específico) un carácter de vehículo que puede transportar ideas, tal como se observa a continuación en la Figura 5.
En el ejemplo, el mapeo icónico de la seña derramar (ver Figura 5b) señala un dominio concreto a la forma lingüística, donde cada uno de los dedos representa a las instituciones en las que está presente la lengua de señas (policía, medicina, derecho, universidad, etc.), tal como se ejemplifica en la figura $5 \mathrm{~d}$.

\section{Doble mapeo}

Se observa un mapeo desde el dominio concreto a la forma lingüística y un mapeo desde un dominio abstracto a un dominio concreto (las ideas son 


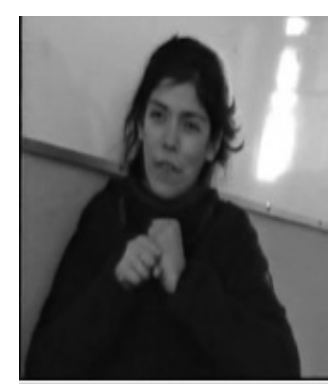

(a) Caballo

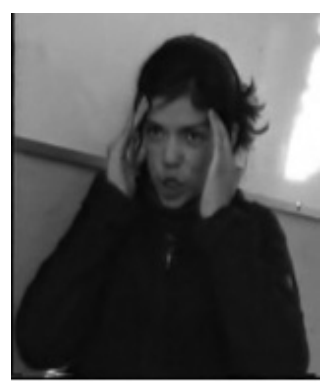

(b) Anteojeras

Figura 6. La persona es un estudiante aplicado. Traducción al lenguaje español: La persona es un caballo.

mapeadas en los objetos). El ejemplo de la Figura 6 ilustra su forma de análisis.

En esta expresión se pueden apreciar los siguientes elementos:

1. Mapeo icónico entre el dominio origen concreto a la forma lingüística: En este primer mapeo se observa un caballo con anteojeras. Dichas anteojeras aluden a un estado de concentración de la persona. Así, el mapeo observado en este caso corresponde al concepto anteojeras es concentración.

2. Mapeo metafórico desde un dominio conceptual concreto a uno abstracto: A partir de la relación establecida en el mapeo icónico se puede apreciar que para este caso la expresión la persona es un caballo, posee un equivalente a la afirmación la persona es un estudiante aplicado. Acá la concentración es mapeada como un movimiento de prestar atención y perseverar en un objetivo, ello es materializado en las anteojeras del animal.

Así, el resultado de este tipo mapeo nos muestra un dibujo icónico del dominio origen: la persona es un caballo (con anteojeras), que denota un equivalente a la idea en lenguaje español: la persona es un estudiante aplicado.

El análisis utilizando doble mapeo permite desprender significados que no se presentan de una manera clara a simple vista. Adicionalmente, devela las diferencias que se establecen entre la lengua oral y de señas en relación a la forma de conceptualización de la metáfora.

\section{Resultados Estudio 2}

La segunda etapa consistió en la aplicación del material audiovisual de 19 metáforas resultantes del Estudio 1, a un grupo de personas sordas usuarias de lengua de señas.

\section{I. Índices Cuantitativos Descriptivos}

En general puede afirmarse que se logra un rendimiento promedio de $85 \%$ frente a la lista de 19 metáforas (ver Tabla 3), lo cual es un dato a favor de la comprensión metafórica en lengua de señas. Los resultados obtenidos permiten apreciar que un gran número de las metáforas evaluadas presenta un nivel de comprensión adecuado por parte de las personas entrevistadas, tal como se aprecia en la Tabla 3.

Es importante destacar además que el descenso en el puntaje general alcanzado por los sujetos, se justifica principalmente por los errores observados en la comprensión de la metáfora 16: un problema se encamina, en la cual sólo una persona logró una adecuada interpretación.

En suma, la información recopilada demuestra que la mayoría de las metáforas fueron comprendidas adecuadamente por gran parte de los sujetos. Esto sugiere que la lengua de señas posee contenido metafórico que logra ser manejado eficientemente por los usuarios tanto a nivel comprensivo como expresivo.

\section{Análisis Cualitativo}

Considerando los conceptos de categorización, mapeo icónico y metafórico, se han podido extraer los siguientes resultados cualitativos, organizados de acuerdo a tópicos relevantes.

1. Traducción. Aún cuando se consideró la sintaxis y morfología de la lengua de señas, la traducción de las respuestas obtenidas ha resultado algo más dificultosa en cuanto a su objetividad y literalidad. Ello porque los conceptos metafóricos que utilizan algunos signantes no siempre concuerdan con un significado claramente definido en lenguaje español. En consecuencia, se puede abstraer la idea presente en la expresión, pero no una transcripción literal (ver Figura 7). 
Tabla 3

Porcentaje de respuestas por metáforas

\begin{tabular}{|c|c|}
\hline Metáforas transcrita en lenguaje español & Comprensión \\
\hline La política es charlatanería & $75 \%$ \\
\hline Las asignaturas se resignan/consienten & $100 \%$ \\
\hline El fracaso es libertad. & $100 \%$ \\
\hline Los aprendizajes vienen y se guardan en la cabeza & $75 \%$ \\
\hline La persona es un caballo & $100 \%$ \\
\hline La oportunidad se toma y se cambia & $92 \%$ \\
\hline El progreso se desenrolla & $100 \%$ \\
\hline El lenguaje se derrama & $92 \%$ \\
\hline No tener tiempo es dar la hora & $100 \%$ \\
\hline Una profesión es un amor & $75 \%$ \\
\hline El cerebro explota & $75 \%$ \\
\hline El pene decae & $100 \%$ \\
\hline Las ilusiones se apartan & $83 \%$ \\
\hline Un problema se encamina & $8 \%$ \\
\hline El reto es una guerra & $92 \%$ \\
\hline Los problemas se lavan & $75 \%$ \\
\hline El cansancio está en la frente & $100 \%$ \\
\hline Las ideas son objetos separables & $83 \%$ \\
\hline Los obstáculos se dejan en el camino & $92 \%$ \\
\hline
\end{tabular}

En esta secuencia, la expresión consiste en una barrera de protección que la persona denominó como "antivirus", el cual es un muro que la protege de amonestaciones. Estas amonestaciones rebotan en el muro, y son desviadas hacia otra persona que aparentemente sería la responsable. El mensaje no se encuentra expresado en términos que logren ser transcritos literalmente desde lengua de señas al lenguaje español.

Podría pensarse en una metáfora análoga en lenguaje español, similar a los problemas me rebotan. Sin embargo, la idea que subyace a esta metáfora en lengua de señas abarca aún otros dominios, pues refiere además a la importancia de responsabilizar a las personas adecuadas frente a un problema.

Es por esto que resulta importante consignar que la traducción metafórica en lenguaje español corresponde sólo a equivalentes aproximados que capturan algunas ideas y en ocasiones pueden ignorar otros detalles presentes en el mensaje.

2. Fusión de señas. Este fenómeno se encuentra presente de manera reiterada en las expresiones espontáneas de los participantes, y se acentúa al momento de explicar lo que comprendieron en una determinada expresión metafórica.

\section{Ejemplo:}

Metáfora original: El cerebro explota (ver Figura 8$)$.

Interpretación del sujeto: Aquello dificil de aprender causa dolor de cabeza (ver Figura 9).

El mensaje graficado en la Figura 9 alude metafóricamente a la complejidad de ciertos contenidos que se traducen en un dolor de cabeza, no porque efectivamente duela la cabeza, sino más bien por el cansancio que pueden ocasionar.

La Figura 9c muestra una mezcla de dos conceptos: dolor y cabeza que dan origen a una nueva seña conservando la misma idea. En la Figura 9c se observa que la fusión espontánea de dolor + cabeza conserva los elementos centrales de ambas señas (dolor y cabeza), pero las concentra en un solo gesto único. Esta seña correspondería a lo que frecuentemente podría estar compuesto por dos conceptos lingüísticos distintos y separados ${ }^{4}$, como se muestra en la Figura 10.

\footnotetext{
4 Las fotografías de la Figura 10 y de la Figura 14a no corresponden a una participante del estudio. Se presenta a una persona voluntaria demostrando el gesto correspondiente.
} 


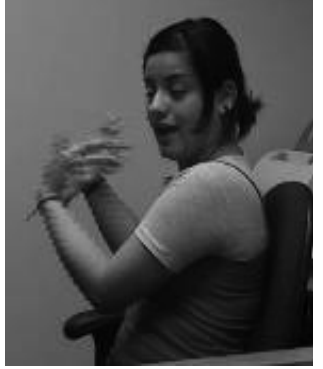

(a) Reto

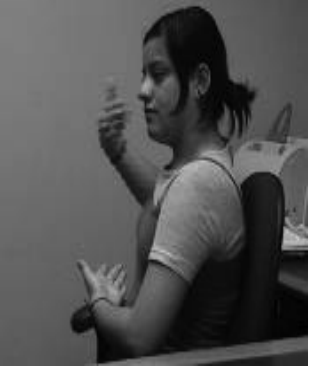

(b) Bajar un muro de contención

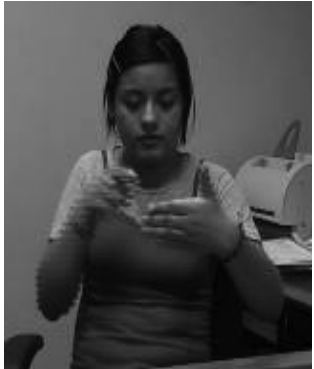

(c) Llegada del proyectil (reto) al muro

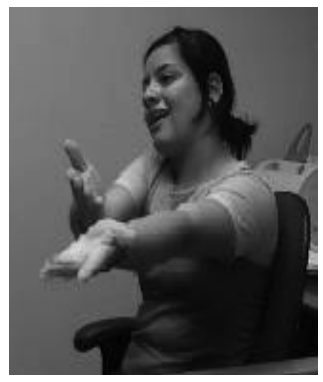

(d) Rebote del proyectil

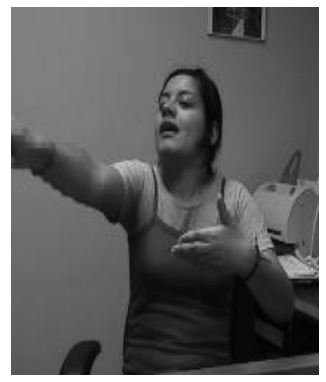

(e) El proyectil es direccionado hacia los verdaderos responsables

Figura 7. Traducción a lenguaje español: Barrera ante dificultades y problemas.

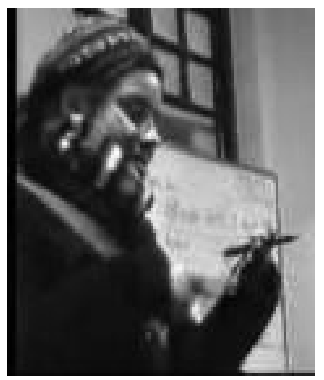

(a) Leer, leer

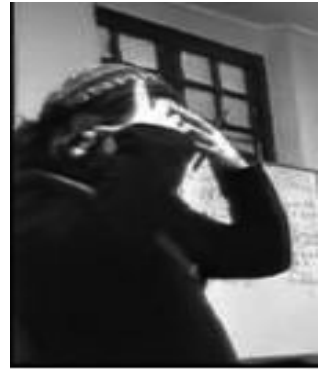

(b) Hinchar cabeza

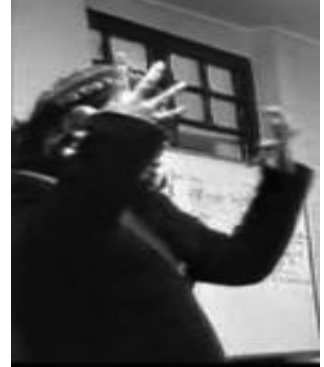

(c) Explotar

Figura 8 .

3. Matices de comprensión. Las ideas expresadas en una metáfora presentan diversos matices en cada entrevistado, sin interferir en la comprensión del concepto central.

Ejemplo:

Metáfora original en lenguaje español: Un problema se encamina. Contenido meta: Desligarse de una increpación (ver Figura 11).

Interpretación del sujeto: Un reto es una crítica que se puede evitar tomando otro camino (ver Figura 12).

Considerando la metáfora en su contexto, la persona ha interpretado el reto como una crítica. Esto le lleva a optar por otro camino que se encuentre libre de retos y por tanto, de críticas.
Se puede observar un elemento común en diversas interpretaciones, que consideran un problema como algo desagradable que puede evitarse.

4. Presencia de oralidad. Aún cuando los sujetos entrevistados no habían sido educados con modalidad oralista, la presencia de este tipo de emisiones se manifiesta reiteradamente. Estas palabras son emitidas espontáneamente y sirven como complemento al mensaje, tal como se muestra en la Figura 13.

A pesar que la seña indica claramente desenrollar, dentro del contexto de comunicación la persona emite oralmente desarrollo, para indicar que desenrollar es análogo a desarrollar. De esta manera, el mensaje está dado por la seña (y su mapeo) en 


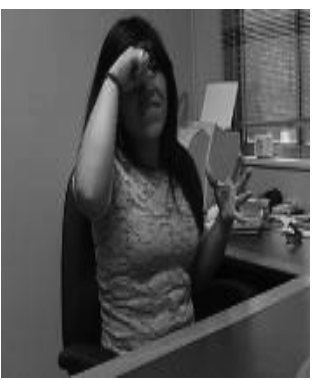

(a) Dificil

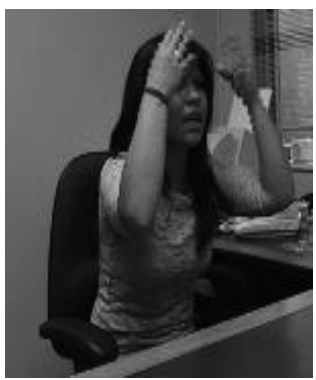

(b) Aprender

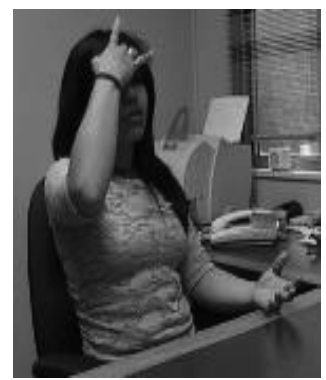

(c) Dolor de cabeza (fusión de términos dolor y cabeza)

Figura 9 .

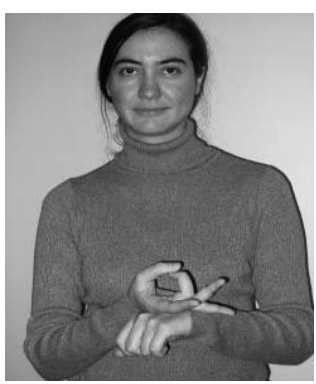

(a) dolor

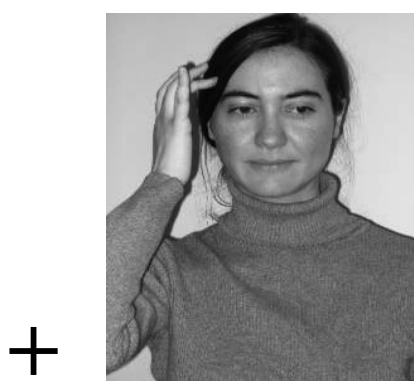

(b) Cabeza

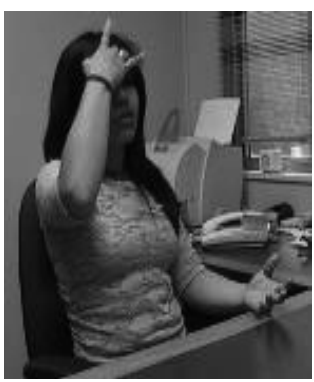

(c) Dolor de cabeza

Figura 10.

complemento con la oralidad. Con esto se indica que el desarrollo es algo progresivo, que se produce en el tiempo (ver mapeo de la seña orientado hacia adelante). Este tipo de interpretación se facilita por el mapeo. En el se pueden apreciar cualidades positivas relacionadas con un avance progresivo en el tiempo respecto de objetivos propuestos. Dichas cualidades no podrían desprenderse desde la seña desarrollar. Tal como se muestra en la Figura 14, los conceptos de temporalidad no son claramente observables en la seña literal correspondiente a desarrollar.

Un nuevo ejemplo de complemento de la oralidad lo constituye el que se presenta en la Figura 15.
La entrevistada se encuentra signando reloj o bien hora, sin embargo, se puede oír que adicionalmente vocaliza no tengo tiempo (con sus particulares imprecisiones articulatorias).

Si se consideran los ejemplos presentados, se puede observar cómo las emisiones articulatorias de los sujetos sordos también participan en la comprensión del mensaje, ya sea complementando o cambiando el sentido del mismo. Por una parte, el ejemplo de la Figura 13 permite apreciar que la oralidad cambia el significado literal para aportarle un sentido metafórico. Mientras que en el ejemplo de la Figura 15, estas emisiones complementan el mensaje entregado, mediante nuevas claves que enriquecen su comprensión. 


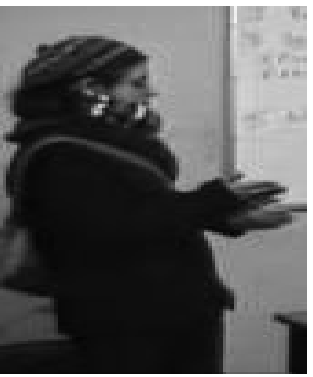

(a) Camino

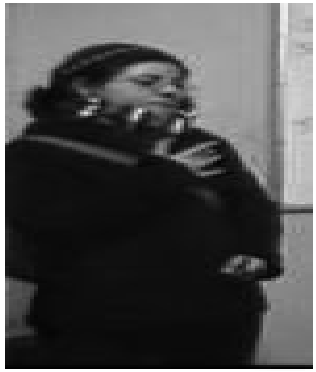

(b) A mi no problemas

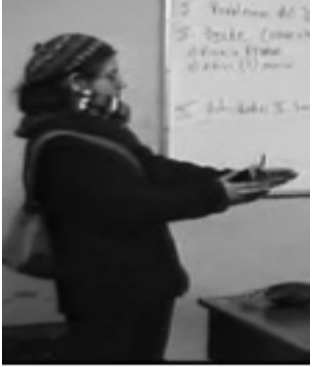

(c) Encaminar

Figura 11.

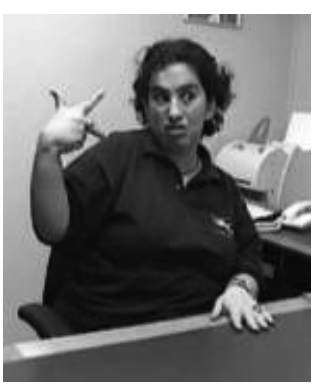

(a) Reto

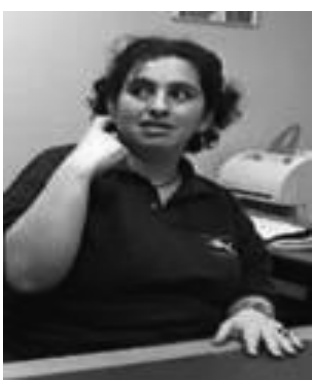

(b) Crítica

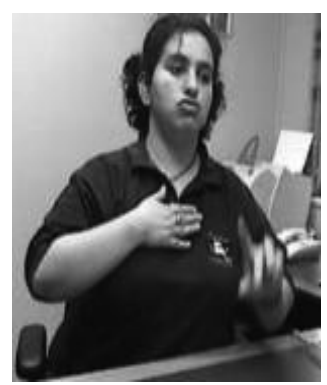

(c) Yo

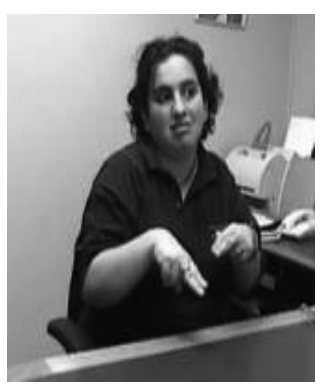

(d) Otro

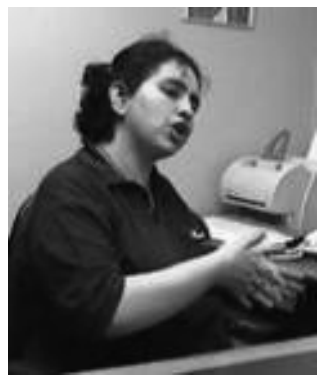

(e) Camino

Figura 12.

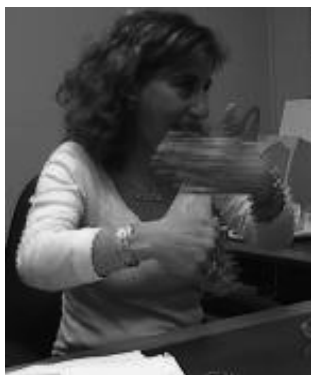

Desenrolla

Figura 13. Expresión señada: Desenrollar. Expresión oral: Desarrollo. 

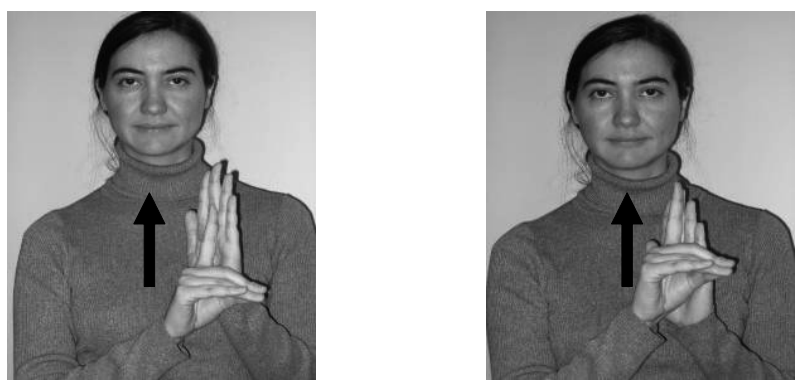

(a) Desarrollo ${ }^{6}$

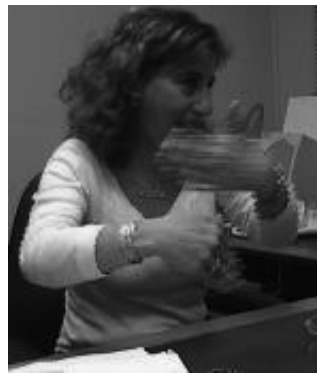

(b) Desenrollar (entendido como "desarrollo")

\section{Figura 14.}

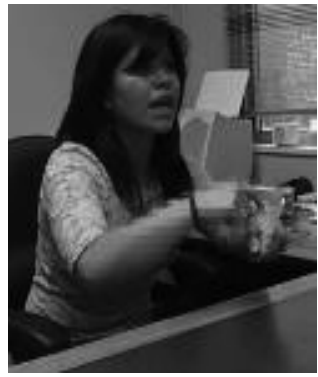

Reloj-hora

Figura 15. Expresión signada: Hora. Expresión oral: No tengo tiempo.

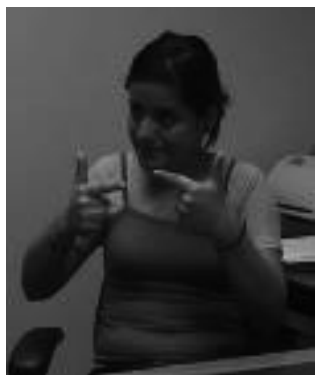

(a) Politica

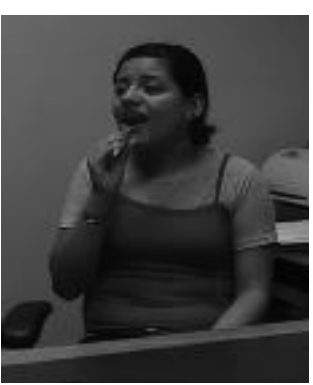

(b) Hablar (En exceso)

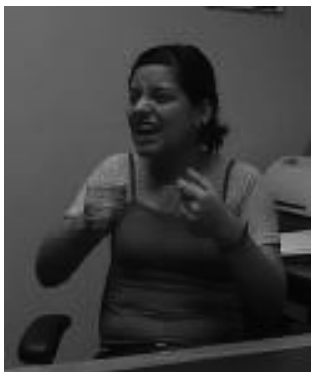

(c) Charlatanería

Figura 16.

6 La seña desarrollo corresponde a una secuencia de la configuración del alfabeto manual correspondiente al fonema $/ d /$. Considera un desplazamiento de dicho fonema desde el plano inferior al superior. 


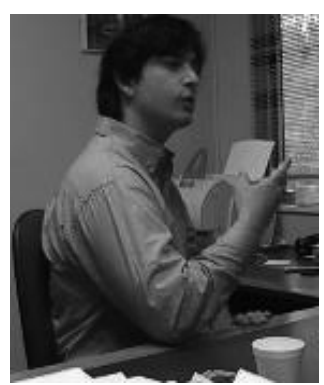

(a) Política

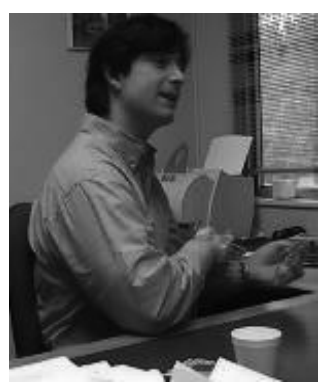

(b) Familia

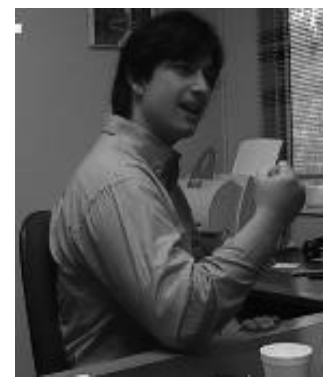

(c) Mezquino

Figura 17.

5. Rol del contexto. Este punto se torna relevante cuando el usuario otorga un determinado contexto en base a su experiencia particular. A partir de esto se desprenden diversas interpretaciones que participan en la comprensión, llegando incluso a cambiar el sentido de esta.

Ejemplo:

Metáfora original: La política es charlatanería. (ver Figura 16)

Interpretación del sujeto: Las familias que prefieren la política son mezquinas. (ver Figura 17)

En esta secuencia (Figura 17) el participante supone erróneamente que la familia de la persona (presente en el video) prefiere la política y por tanto es un grupo familiar mezquino. Adicionalmente, el entrevistado supone que esta preferencia se produce en desmedro de una educación de calidad para su hija/o. Al consultarle las razones que lo llevan a inferir esta interpretación, el participante agrega que ha conocido experiencias de familias sordas que por dedicarse a la política y a "hablar de más" han dejado a sus hijos sin educación. De esto concluye que las familias que no se encargan de una adecuada educación para sus hijos y que prefieren la política, son mezquinas.

\section{Conclusiones y Discusión}

Este estudio parte de la ausencia de investigaciones previas en el área, sumada a una afirmación tácita del ambiente de que la lengua de señas sería literal y no metafórica. Por esto ha considerado la particular configuración de la Lengua de Señas Chilena. Los antecedentes recopilados han reportado elementos empíricos a favor de la expresión metafórica en Lengua de Señas Chilena. Sus resultados han demostrado la existencia de expresiones metafóricas, metonimias y fusiones de señas; todas ellas arraigadas fuertemente en el esquema y experiencia corporal del sujeto sordo. Por ello se sugiere que esta lengua posee capacidad para la expresión de conceptos abstractos mediante la metáfora.

Los resultados de la primera etapa del estudio permiten una categorización metafórica utilizando dominios meta como: la mente es un contenedor, las ideas son objetos, los problemas son objetos, fuerza es arriba, negativo es abajo, un reto es una guerra, la vida es un camino. Además, estas expresiones pueden clasificarse de la siguiente manera:

1. Metáforas corporales: Este tipo de metáforas se encuentran relacionadas principalmente con un mapeo espacial del tiempo y emociones. Estas se conceptualizan en el cuerpo del hablante, el cual funciona como punto de referencia en la expresión de cada signo.

1.1. Metáforas espaciales sobre el tiempo: Aquello relacionado con el futuro se proyecta hacia delante del individuo y el pasado hacia atrás. Acá, el usuario funciona como un punto de referencia. El futuro está ubicado delante de la persona de referencia, el pasado detrás y el presente está co-ubicado con la persona. La distancia en el espacio se corresponde con un tiempo determinado por el usuario y a mayor distancia, mayor será el tiempo asignado a un evento.

1.2. Metáforas espaciales sobre lo deseado: En este tipo de conceptualización lo bueno se ubica arriba del sujeto y lo malo se encuentra orientado hacia abajo. A menor distancia del punto del usuario, mayor intensidad de los anhelos proyectados, sean estos positivos o negativos. 
2. Metáforas lingüistico-culturales: Este tipo de metáforas corresponde principalmente a expresiones propias de la cultura sorda. Constituyen formas que guardan escasa relación con el lenguaje español (ejemplo: la persona es un caballo).

\subsection{Metáforas espaciales sobre el transporte y} manejo de la información: Es habitual que el usuario de Lengua de Señas Chilena le otorgue a esta un carácter de vehículo de información. Las ideas son conceptualizadas como objetos y ellas permiten su manipulación y transporte a través del lenguaje (la mano del usuario). La forma de funcionamiento de este vehículo consiste en impregnar al lenguaje (la mano del usuario) de las ideas (objetos) que desean ser comunicados.

En relación al Estudio 2, se han reportado antecedentes acerca de la comprensión de expresiones metafóricas de los sujetos sordos. Se tomarán algunos tópicos principales:

1. Transcripción: El análisis de las expresiones de cada participante enfrentó dificultades relacionadas a su transcripción. Por ello la interpretación presentada corresponde en algunos casos a referentes aproximados y no a una traducción literal. De esto se sigue la posibilidad de ignorar detalles importantes para el usuario de la lengua.

Lo anterior sería producto de la sintaxis, presencia de oralidad en las emisiones de los participantes e iconicidad de las señas. Particularmente esta última juega un rol importante. La alta recurrencia de las expresiones metafóricas a señas icónicas le aporta variados detalles que constituyen información adicional. Estos accesorios icónicos pueden incluso llegar a cambiar el sentido de una expresión. Puesto que constituyen numerosos detalles del objeto referido y se encuentran incorporados en una misma seña, no siempre encuentran un referente en lenguaje español.

2. Matices de comprensión y rol del contexto: Se apreciaron matices en la comprensión metafórica. Es probable que ellos estén relacionados con el contexto en el cual se desarrolla la expresión. Se propone que en lengua de señas, la metáfora sugiere y por tanto mantiene abierta la posibilidad que el destinatario interprete una expresión de diversas maneras según el contexto en que la incorpore.

3. Presencia de oralidad: Aún cuando los participantes reportaron no haber sido sometidos al aprendizaje sistemático del lenguaje oral, se evidenció un uso frecuente de emisiones orales como modalidad complementaria. A pesar de sus imprecisiones articulatorias, ellas guardan relación con la seña en curso. Además de complementar el mensaje, pueden llegar a cambiar el sentido otorgado por el usuario.

4. Fusión de señas: Los hallazgos de esta investigación reportan una alta recurrencia del usuario a la fusión espontánea de señas a lo largo de su discurso. Se ha visto que los entrevistados reconocen la existencia de este fenómeno dentro de sus experiencias comunicativas y también destacan la frecuencia de estas expresiones que reconocen "informales" pero fácilmente comprensibles.

Para este fenómeno, la propuesta de doble mapeo no permite un abordaje claro. Esto arroja dudas acerca de la naturaleza de estas expresiones. Principalmente porque ella presenta una nueva seña que ha sido creada a partir de la fusión de dos conceptos.

Al respecto, los antecedentes recopilados no permiten apreciar con certeza si estas corresponden a una fusión de señas que da origen a una nueva forma lingüística o bien constituyen una forma particular de metáfora. Visto así, esta situación plantea dos posibles modos de abordaje. Por una parte se podría especular que estas señas constituyen una forma especial de metáfora donde se unen dos tipos diferentes de iconicidad con una metáfora. Como una explicación alternativa se puede sugerir que este fenómeno no necesariamente constituye metáfora y correspondería a una nueva forma lingüística que puede comprenderse incluso literalmente. Dadas estas observaciones, es probable que ellas se desprendan de esquemas fuertemente arraigados en la persona. Siendo este el caso, podría tratarse de un nuevo concepto que permite la interpretación literal de una idea abstracta.

Los antecedentes reportados suponen una diferencia importante entre ver y escuchar el lenguaje. De esto se siguen cambios en la forma de entender y organizar el medio circundante. Para el sujeto sordo, la facultad de ver el lenguaje le da la posibilidad de trasformarlo en una herramienta distinta. Por tratarse de un lenguaje presente en las manos, le ofrece la posibilidad de manipularlo y así operar de manera concreta con los elementos presentes en el medio.

De lo anterior se sigue la importancia de la iconicidad como un recurso lingüístico característico de la experiencia del sujeto sordo. Por ejemplo, el usuario de lengua de señas puede manejar un muro como si 
fuera un antivirus, una barrera o del modo que estime conveniente, destacando las características, cualidades y detalles que le parezcan relevantes a través de un dibujo icónico del mismo y sólo serán accesibles simultáneamente mediante la visión. Esto viene a reforzar la idea de la lengua de señas como una lengua icónica que deja entrever detalles propios de conceptos presentes en el medio. Pero no avala la tesis de su pobreza para la expresión de elementos abstractos. Principalmente porque se ha visto que la manipulación icónica permite apreciar simultáneamente características del medio que pueden servir como punto de partida para ideas abstractas mediante un uso figurado.

Los argumentos expuestos hasta acá permiten apreciar una consecuencia metodológica relacionada principalmente con el doble mapeo como medio de análisis de expresiones metafóricas e iconicidad en lengua de señas. Este manifiesta ciertas carencias en relación a la información adicional que aporta una seña icónica. Un ejemplo de esto constituye la expresión la persona es un caballo (la persona es un estudiante aplicado). En este ejemplo priman las cualidades del accesorio (en este caso las anteojeras) por sobre una interpretación figurada del gesto.

Respecto del funcionamiento de la lengua de señas y del lenguaje en general se pueden desprender algunas ideas importantes. Una de ellas guarda relación el modo de abordaje de la temática. En general en el presente estudio las expresiones metafóricas en lengua de señas siguen siendo estudiadas con recursos del lenguaje español. Esto puede apreciarse en los ejemplos expuestos, donde se han categorizado metáforas a partir de una traducción al lenguaje español. De lo anterior se siguen dudas respecto de aquello que debe entenderse como metáfora en lengua de señas. En este sentido es difícil determinar un punto común entre ambas modalidades comunicativas.

Para finalizar, el estudio ha reportado la presencia de metáforas en Lengua de Señas Chilena. La metáfora no sólo se apoya en el contexto, también es importante la experiencia del sujeto. Por eso es interesante una mirada ya no sólo desde la expresión misma de la seña en contexto. Se hace necesario considerar la experiencia del usuario para dar mayor sentido no sólo a sus expresiones metafóricas sino además a la creación de nuevas señas.

La manipulación concreta del lenguaje abre una ventana a una modalidad distinta de abordaje. Por eso se propone que el estudio de la metáfora en lengua de señas es un tema incipiente que abre una serie de interrogantes metodológicas y teóricas importantes para ser abordadas en futuras investigaciones.

\section{Referencias}

Boatner, M. \& Gates, J. (1975). A dictionary of american idioms. New York: Barron's Educational Series.

Brennan, M. (1994). Pragmatics and productivity. En I. Ahlgren, B. Bergman \& M. Brennan (Eds.), Perspectives on sign language usage: Papers from the Fifth International Symposium on Sign Language Research, Vol. 2 (pp. 371-390). Durham: International Sign Linguistics Association.

Brennan, M. (2005). Conjoining word and image in British Sign Language (BSL): An exploration of metaphorical signs in BSL. Sign Languages Studies, 5, 360-384.

Conrad, R. (1979). From gesture to language in hearing and deaf children. Washington, DC: Gallaudet University Press.

Fauconnier, G. (1994). Mental spaces aspects of meaning construction in natural language. New York: Cambridge University Press.

Furth, H. (1973). Pensamiento sin lenguaje: Implicancias psicológicas de la sordera. Madrid: 1981.

Gilbertson, M. \& Kamhi, A. (1995). Novel word learning in children with hearing-impairment. Journal of Speech and Hearing Research, 38, 630-641.

Giuranna, R. \& Giuranna, G. (2000). Poesia in LIS: Iconicità e arbitrarietà, concreto e astratto. En C. Bagnara, P. Chiappini, M. P. Conte \& M. Ott (a cura di), Viaggio nella città invisibile. Atti del $2^{\circ}$ Convegno nazionale sulla Lingua Italiana dei Segni (pp. 341-348). Pisa: Edizioni del Cerro.

Ibáñez, A., Becerra, C., López, V., Sirlopú, D. \& Cornejo, C. (2005). Iconicidad y metáfora en el lenguaje chileno de signos (LENSE): Un análisis cualitativo. Revista Electrónica de Investigación y Evaluación Educativa, 11(1). Recuperado el 19 de Diciembre de 2005, desde http://www.uv.es/RELIEVE/v10n2/RELIEVEv11n1_2. htm

Iran-Nejad, A., Rittenhouse, R. \& Morreau, L. (1981). Metaphor and conservation in deaf and hard-of-hearing children. American Annals of the Deaf, 126, 450-453.

Jarque, M. J. (2005). Double mapping in metaphorical expressions of thought and communication in Catalan Sign Language (LSC). Sign Language Studies, 5, 292-318.

Johnson, D. \& Myklebust, H. (1967). Learning disabilities. Educational principles and practices. New York: Grune \& Stratton Inc.

Lakoff, G. \& Johnson, M. (1999). Philosophy in the flesh. The embodied mind and its challenge to western thought. New York: Basic Books.

McNeill, D. (1992). Hand and mind: What gestures reveal about thought. Chicago: University of Chicago Press.

Pizzuto, E., Russo, T. \& Giuranna, R. (2001). Italian Sign Language (LIS) poetry: Iconic properties and structural regularities. Sign Language Studies, 2(1), 84-112.

Rittenhouse, R. \& Kenyon, P. (1991). Conservation and metaphor acquisition in hearing-impaired children. Some relationships with communication mode, hearing acuity, schooling and age. American Annals of the Deaf, 136, 313-320.

Russo, T. (2005). A crosslinguistic, cross-cultural analysis of metaphors in two Italian Sign Language (LIS) registers. Sign Languages Studies, 5, 333-361.

Takashi, S. (1999). Metaphor interpretation by students with hearing impairements. Japanese Journal of Special Education, 37(2), 59-69.

Taub, S. (2001). Language from the body. Cambridge: Cambridge University Press.

Wilcox, P. (1993). Metaphorical mappings in American Sign Language. PhD. Dissertation. Albuquerque: University of New Mexico. 
Wilcox, P. (2000). Metaphor in American Sign Language. Washington, DC: Gallaudet University Press.

Wilcox, P. (2005). What do you think? Metaphor in thought and communication domains in American Sign Language. Sign
Language Studies, 3, 267-293.

Wolgelmuth, K., Kahmi, A. \& Lee, R. (1998). Metaphor performance in children with hearing impairment language. Language, Speech \& Hearing Services in Schools, 29, 216-232.

Fecha de recepción: Enero de 2007.

Fecha de aceptación: Diciembre de 2007. 